\title{
Desinfección de cariopses y regeneración de plantas de Spartina argentinensis
}

\author{
Mirian S. Bueno ${ }^{1}$, Susana R. Feldman ${ }^{1,2}$ y Juan P. Ortiz \\ ${ }^{1}$ Cátedra de Biología, Facultad de Ciencias Agrarias, Universidad Nacional de Rosario, C.C. 14, s2125zaa \\ Zavalla, Argentina. ${ }^{2}$ Consejo de Investigaciones de la Universidad Nacional de Rosario (CIUNR). ${ }^{3}$ Cátedra \\ de Química Biológica. Consejo Nacional de Investigaciones Científicas y Técnicas (CONICET).
}

\begin{abstract}
M.S. Bueno, S.R. Feldman, and J.P. Ortiz. 2007. Cariopsis disinfection and plant regeneration of Spartina argentinensis. Cien. Inv. Agr. 34(3): 231-236. A protocol for disinfection and in vitro regeneration of Spartina argentinensis was developed. The lowest percentage of contamination was obtained after treating caryopses with $90^{\circ}$ ethanol for $60 \mathrm{~s}$ and 20 min immersion in $2.5 \%$ sodium hypochlorite $(\mathrm{NaOCl})$ plus $0.1 \%$ Tween 20 . Murashige and Skoog (MS) media was used for callus induction, supplemented with $0.5 \mathrm{mg} \cdot \mathrm{L}^{-1}$ of 2 , 4 dichlorophenoxy acetic (2,4-D) and $1 \mathrm{mg} \cdot \mathrm{L}^{-1}$ of indole-3-acetic acid (IAA). The highest proportion (20\%) of shoot regeneration was achieved with MS media plus $0.25 \mathrm{mg} \cdot \mathrm{L}^{-1}$ of bencyl aminopurine (BAP), whereas $0.5 \mathrm{mg} \cdot \mathrm{L}^{-1}$ naphtalenacetic acid (NAA) was used for root induction. Plants were regenerated via organogenesis. To our knowledge, this is the first report of a protocol for in vitro plant regeneration of S. argentinensis, and it is the initial stage required for obtaining somaclonal variations.
\end{abstract}

Key words: In vitro regeneration, organogenesis, Spartina.

\section{Introducción}

El espartillo, Spartina argentinensis Parodi (Poaceae: Chloridaeae), es una de las especies dominantes de las comunidades halófilas de distintas áreas de Argentina. Forma matas de altura variable, de 0,5 - 1,4 m de altura. Aunque produce abundantes panojas durante el verano, se reproduce principalmente en forma agámica por rizomas (Feldman, 2003).

Los espartillares se utilizan para cría de ganado vacuno, a pesar del alto grado de lignificación de sus hojas, lo que reduce la digestibilidad. La obtención de líneas de espartillo caracterizadas por un menor contenido de lignina es una de las alternativas para mejorar la digestibilidad del forraje y al mismo tiempo mejorar la oferta forrajera en las áreas dónde esta especie se encuentra presente.

Recibido 13 junio 2007. Aceptado 05 septiembre 2007.

1Dirigir correspondencia a M. S. Bueno: mbueno@unr.edu.ar
Estudios previos (Larkin y Scowcroft, 1981) demostraron que durante las sucesivas mitosis que se producen en cultivo in vitro pueden ocurrir importantes modificaciones genéticas en las células. Algunas se manifiestan como mutaciones heredables, generando variaciones somaclonales. Por consiguiente, el cultivo de tejidos es una herramienta útil para el mejoramiento de especies vegetales y se ha utilizado en especies forrajeras nativas (Echenique et al., 2001; Kothari et al., 2005).

La elección del explante es fundamental para el establecimiento de un cultivo in vitro (Roca y Mroginsky, 1991). En gramíneas se ha regenerado plantas utilizando embriones inmaduros, inflorescencias inmaduras y cariopses maduros (Dutta Grupta et al., 1999; Echenique et al., 2001). Sin embargo, algunos de estos explantes sólo se pueden obtener en determinadas épocas del año. En el género Spartina, se ha logrado regenerar plantas a partir de cultivo in vitro de cariopses maduros 
(Li et al., 1995, Li and Gallager, 1996; Wang et al., 2003). Sin embargo, en S. argentinensis, la contaminación de sus cariopses por Alternaria alternata, Fusarium graminearum y Bipolaris sorokiniana y otros hongos dificulta la utilización de los mismos para iniciar los cultivos. Algunos de estos hongos se han descrito como endógenos (Feldman et al., 2004). Este trabajo tuvo como objetivo estudiar diferentes tratamientos de desinfección de cariopses de espartillo ( $S$. argentinensis) y evaluar su potencial de regeneración in vitro.

\section{Materiales y métodos}

Se trabajó con cariopses maduros de $\mathrm{S}$. argentinensis, sin pálea ni lemma, extraídos de panojas cosechadas en un espartillar ubicado en Pérez, provincia de Santa Fe, Argentina ( $32^{\circ} 45^{\prime}$ $\left.\mathrm{S} ; 60^{\circ} 35^{\prime} \mathrm{W}\right)$. Se realizaron dos experimentos de desinfección de cariopses: 1. Inmersión durante 20 min en hipoclorito de sodio $\mathrm{NaOCl}$ al 1,5 y $2,5 \%(\mathrm{v} / \mathrm{v})$ (Cloro Argentina S.A., $5,5 \mathrm{~g} \cdot \mathrm{L}-1$ de cloro) con o sin el agregado de Tween 20 (0,1\%). 2. Inmersión en $\mathrm{NaOCl}$ 2,5\% con Tween $20(0,1 \%)$ durante 20 o $30 \mathrm{~min}$ a temperatura ambiente con o sin inmersión en etanol $90^{\circ}$ por $60 \mathrm{~s}$. Se utilizaron cinco repeticiones por tratamiento, con 20 cariopses por repetición. Luego de cada tratamiento, los cariopses se lavaron con abundante agua estéril y se los sembró en placas de Petri con medio Murashigue Skoog (MS 1962), sin hormonas, suplementados con $30 \mathrm{~g} \cdot \mathrm{L}^{-1}$ de sacarosa, $7 \mathrm{~g} \cdot \mathrm{L}^{-1}$ de agar, pH 5,8. Los cultivos se incubaron en oscuridad a $23 \pm 2^{\circ} \mathrm{C}$ durante 30 días.

La proporción de cariopses contaminados a los 7 días de la siembra in vitro se evaluó mediante análisis de varianza (ANDEVA) y los promedios se separaron según Duncan (Statistica 5.0). Previo a los análisis, los valores porcentuales se transformaron en arcoseno $\sqrt{ } \mathrm{x}$.

Los cariopses libres de contaminación se transfirieron a tubos de ensayo de $20 \mathrm{ml}$ con diferentes medios para la inducción de callos (Cuadro 1) y se mantuvieron en oscuridad a $25^{\circ} \mathrm{C}$, durante 30 días. Los callos producidos se repicaron a medios para la inducción de vástagos con diferentes concentraciones de bencil amino purina (BAP) y se incubaron a $25^{\circ} \mathrm{C}$, con un fotoperíodo de $16 \mathrm{~h}$ (Cuadro 1 ). Los vástagos obtenidos se separaron y la regeneración de raíces se obtuvo en medio con ácido naftalen acético (ANA) (Cuadro 1).

Las frecuencias de formación de callos y vástagos para los distintos medios ensayados, se compararon mediante prueba de homogeneidad con aplicación de Chi cuadrado $\left(\lambda^{2}\right)$ (SAS Institute, Cary, NC, EUA).

Se realizaron estudios histológicos para determinar la vía de regeneración de los explantes. Las muestras se fijaron en FAA (10\% formol, 5\% ácido acético, 50\% etanol y $35 \%$ agua) y posteriormente se deshidrataron en concentraciones ascendente de etanol (1 $\mathrm{h}$ en cada una de las siguientes soluciones de etanol: $70^{\circ} ; 80^{\circ} ; 90^{\circ}, 96^{\circ}$ y $30 \mathrm{~min}$ en $100^{\circ}$ ). Previo a la inclusión en parafina, las muestras se clarificaron con xilol, realizando un paulatino desplazamiento del etanol $100^{\circ}$ por el xilol. Se realizaron cortes con micrótomo tipo Minot (18$20 \mu \mathrm{m}$ de espesor) y se colorearon con safranina (30 min) y fast-green (60 s), que tiñe de color azul-verdoso las zonas celulósicas y de color fucsia a las zonas lignificadas (Johansen, 1940, Dizeo de Strittmater, 1979). Los preparados montados con bálsamo de Canadá, se observaron y se fotografiaron con microscopio óptico.

Cuadro 1. Composición de los medios de cultivo utilizados para inducción de callos (M), inducción de vástagos (V) y enraizamiento (R) de Spartina argentinensis.

Table 1. Composition of the media used for callus induction $(M)$, shoot $(V)$ and root $(R)$ regeneration of Spartina argentinensis.

\begin{tabular}{lcccc}
\hline \multirow{2}{*}{ Medios } & \multicolumn{4}{c}{ Reguladores de crecimiento ${ }^{1}, \mathrm{mg}^{2} \mathrm{~L}^{-1}$} \\
\cline { 2 - 5 } & $2,4-\mathrm{D}$ & $\mathrm{BAP}$ & $\mathrm{ANA}$ & $\mathrm{AIA}$ \\
\hline Inducción de callos: & & & \\
M1 & 0,5 & 0,05 & 1,00 & \\
M2 & 0,5 & & & 1,00 \\
M3 & 0,5 & 0,05 & & \\
\hline Inducción & de vástagos: & & \\
V1 & & 0,25 & \\
V2 & & 0,50 & \\
\hline Enraizamiento: & & & \\
R & & 0,50 & \\
\hline
\end{tabular}

${ }^{1}$ BAP, 6-bencil amino purina; ANA, ácido naftalén acético; AIA, ácido indol acético; 2,4-D, ácido dicloro fenoxi acético. 


\section{Resultados y discusión}

La desinfección de los explantes con $\mathrm{NaOCl}$ más $0.1 \%$ de Tween 20 como humectante disminuyó significativamente $(\mathrm{p}=0,001)$ la contaminación a los 7 días de incubación. No hubo respuesta diferencial a las concentraciones de $\mathrm{NaOCl}$, posiblemente debido al marcado efecto del humectante que permitió una eficiente desinfección aún con la menor concentración de $\mathrm{NaOCl}$ (Figura 1).

Lacontaminación disminuyó significativamente $(\mathrm{p}<0,05)$ en función del tiempo de inmersión en $\mathrm{NaOCl}$ y con el tratamiento con etanol, sin manifestarse interacción entre las variables analizadas (Figura 2). A diferencia de reportes previos, los mejores resultados se obtuvieron utilizando una mayor concentración de etanol $90^{\circ}$ (Li y Gallagher, 1996). Posiblemente esto se debió a que los cariopses de $S$. argentinensis presentan mayor contaminación fúngica (Feldman et al., 2004).
La presencia de callos se observó a los 7 días de incubación de los explantes en los medios de inducción. En la Figura 3 se observa la evolución porcentual de producción de callos durante los primeros cuarenta días de cultivo. La obtención de callos fue máxima a los 30 días de iniciado el cultivo, estabilizándose posteriormente. No se detectaron diferencias estadísticas significativas en las frecuencias de inducción de callos entre los medios M1 y M2 (68,8 y 62,5\% respectivamente), respuesta coincidente con los resultados obtenidos previamente para S. alterniflora (Wang et al., 2003). La inducción de callos sólo alcanzó a $37,5 \%$ en el medio 3 , que incluyó $0,5 \mathrm{mg} \cdot \mathrm{L}^{-1}$ de 2,4-D y $0,05 \mathrm{mg} \cdot \mathrm{L}^{-1}$ de BAP, debido a la ausencia de ANA o AIA.

Los estudios histológicos mostraron que la regeneración de vástagos ocurrió vía organogénesis, donde se observa la formación de dos vástagos dentro de la masa del callo, sin zonasembriogénicas ni proembriones(Figura5).

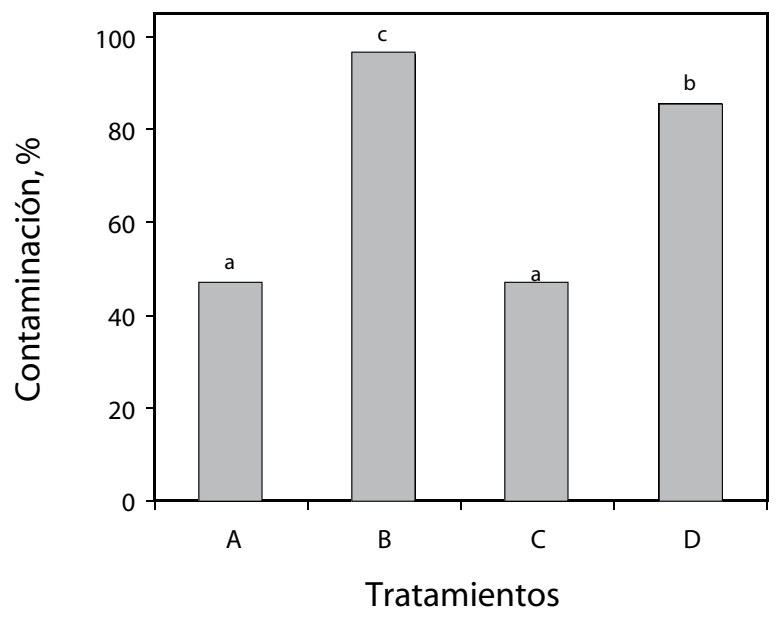

Figura 1. Efecto de la concentración de hipoclorito de sodio y de Tween 20 empleado como tensoactivo en la desinfección superficial de cariopses de Spartina argentinensis. A. Hipoclorito de sodio 1,5\% mas Tween 20. B. Hipoclorito de sodio 1,5\% sin Tween 20. C. Hipoclorito de sodio 2,5\% con Tween 20. D. Hipoclorito de sodio 2,5\% sin Tween 20. (n=5). Promedios seguidos por igual letra no son estadísticamente diferentes entre si según Duncan ( $<<0,05)$.

Figure 1. Effect of sodium hypochlorite concentrations and Tween 20 as humectant on superficial disinfection of caryopses of Spartina argentinensis. A. 1.5\% sodium hypochlorite plus Tween 20. B. $1.5 \%$ sodium hypochlorite. C. $2.5 \%$ sodium hypochlorite plus Tween 20.D. 2.5\% sodium hypochlorite. Means followed by the same letter are not statistically different according to Duncan $(p<0.05)$. 


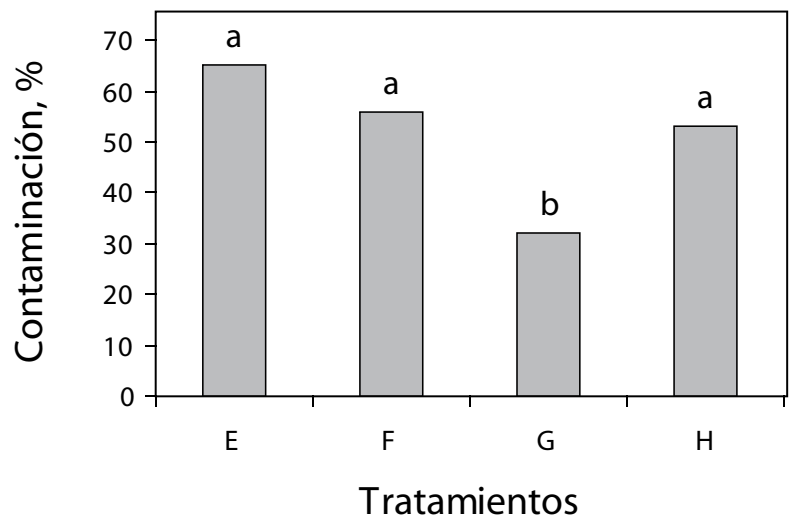

Figura 2. Efecto de los diferentes tratamientos sobre el porcentaje de contaminación de cariopses de Spartina argentinensis. E. 1 min en etanol $90^{\circ}$ y 20 min de inmersión en hipoclorito de sodio 2,5\% con Tween 20. F. Igual a E sin etanol. G. 1 min en etanol $90^{\circ}$ y 30 min de inmersión en hipoclorito de sodio $2.5 \%$ con Tween 20 . H. ídem G, sin etanol. Promedios seguidos por igual letra no son estadísticamente diferentes entre si según Duncan $(\mathrm{p}<0,05)$.

Figure 2. Effect of different treatments on surface contamination of caryopses of Spartina_argentinensis. E. Ethanol $90^{\circ}$ for $60 \mathrm{~s}$ and $20 \mathrm{~min}$ in $2.5 \%$ sodium hypochlorite plus Tween 20. F. Similar to E, but without ethanol. G. Ethanol $90^{\circ}$ for $60 \mathrm{~s}$ and $30 \mathrm{~min}$ in $2.5 \%$ sodium hypochlorite plus Tween 20. H. Similar to G, but without ethanol. Means followed by the same letter are not statistically different according to Duncan $(p<0.05)$.

La misma vía de regeneración de vástagos fue previamente informada para $S$. alterniflora, $S$. cynosuroides y S. patens (Wang et al., 2003; Li et al., 1995, 1996). En otras especies, ej. Eragrostis curvula, y utilizando el mismo explante, la regeneración de vástagos ocurrió vía embriogénica (Echenique et al., 2001) y en Bouteloua gracilis, la regeneración de vástagos se produjo tanto por vía organogénica como embriogénica (Agudo-Santacruz et al., 2000).

De las concentraciones hormonales utilizadas para la regeneración de vástagos, el medio V2 con 0,5 mg.L $\mathrm{L}^{-1}$ de BAP favoreció la mayor respuesta de los explantes, puesto que $20 \%$ de los callos regeneraron vástagos. En el medio V1, con 0,25 $\mathrm{mg} \cdot \mathrm{L}^{-1}$ de BAP, los porcentajes de respuestas fueron inferiores a $12 \%$. Si bien el porcentaje de callos que regeneraron vástagos fue bajo, cada callo diferenció múltiples vástagos, aumentando la eficiencia de regeneración.

La regeneración de raíces se indujo favorablemente con $0,50 \mathrm{mg} \cdot \mathrm{L}^{-1}$ de ANA. Las plantas regeneradas se separaron y se transfirieron a una mezcla de suelo (30\% vermiculita-70\% tierra) en invernadero.

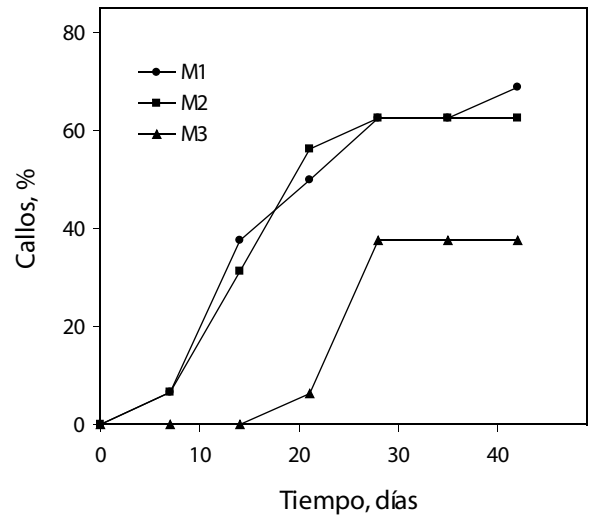

Figura 3. Efecto de distintos medios de cultivo sobre el porcentaje de producción de callos de Spartina argentinensis. $\mathrm{M} 1=0,5 \mathrm{mg} \cdot \mathrm{L}^{-1}$ de $2,4-\mathrm{D} ; 0,05 \mathrm{mg} \cdot \mathrm{L}^{-1}$ de BAP y $1 \mathrm{mg} \cdot \mathrm{L}^{-1}$ de ANA. M2 $=0,5 \mathrm{mg} \cdot \mathrm{L}^{-1}$ de 2,4-D; $1 \mathrm{mg} \cdot \mathrm{L}^{-1}$ de AIA. M3 $=0,5 \mathrm{mg} \cdot \mathrm{L}^{-1}$ de $2,4-\mathrm{D}$ y $0,05 \mathrm{mg} \cdot \mathrm{L}^{-1}$ de BAP. BAP $=6$-bencil amino purina; $\mathrm{ANA}=$ ácido naftalén acético; AIA = ácido indol acético; 2,4-D = ácido dicloro fenoxi acético.

Figure 3. Effect of different media on the percentage of callus production of Spatina argentinensis. $M 1=0.5$ $m g \cdot L^{-1} 2,4-D, 0.05 \mathrm{mg} \cdot \mathrm{L}^{-1} B A$, and $1 \mathrm{mg} \cdot \mathrm{L}^{-1} \mathrm{NAA}$. $M 2=$ $0.5 \mathrm{mg} \cdot \mathrm{L}^{-1}$ and $2,4-D, 1 \mathrm{mg} \cdot \mathrm{L}^{-1}$ IAA. M3 $=0.5 \mathrm{mg} \cdot \mathrm{L}^{-1} 2,4-$ $D, 0.05 \mathrm{mg} \cdot \mathrm{L}^{-1} B A . B A=6$-benzyl-adenine; $N A A=\alpha$ naphtaleneacetic acid; IAA = indole-3-acetic acid; $2,4-D$ = 2,4-dichlorophenoxyacetic acid. 


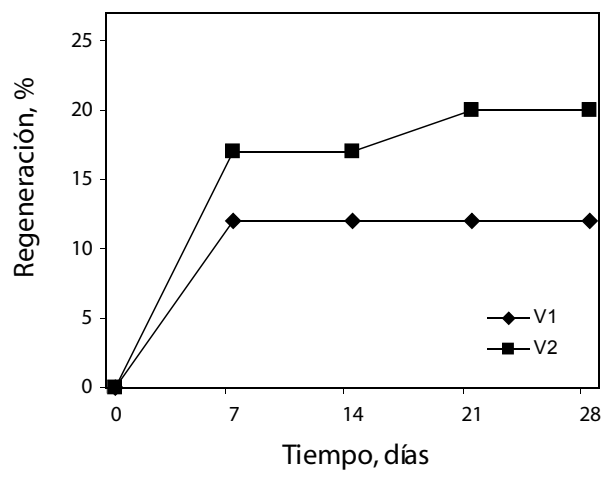

Figura 4. Variación del percentage de regeneración de vástagos de Spartina argentinensis. V1, 0,25 mg $\cdot \mathrm{L}^{-1} \mathrm{BAP}$ (6-bencil amino purina) y V2, 0,5 $\mathrm{mg} \cdot \mathrm{L}^{-1} \mathrm{BAP}$.

Figure 4. Percentage of Spartina argentinensis shoot regeneration using medium $V, 0.25 \mathrm{mg} \cdot \mathrm{L}^{-1} \mathrm{BP}$ (6-benzyladenine) and $V 2,0.5 \mathrm{mg} \cdot \mathrm{L}^{-1} \mathrm{BP}$.

La metodología de desinfección de cariopses estudiada se podría extender a otras especies que presenten altos porcentajes de contaminación fúngica, debido a que permite utilizar el tratamiento combinado de $\mathrm{NaOCl}$ y etanol, que presentan baja toxicidad, a diferencia de otros que utilizan cloruro de mercurio (Wang et al., 2003).

Este trabajo es la primera mención de regeneración de plantas de $S$. argentinensis utilizando cultivo in vitro de cariopses maduros y constituye la etapa inicial para la obtención de variantes somaclonales. De esta forma se espera poder obtener líneas mejoradas en busca de cultivares con una mejor aptitud ganadera. Del mismo modo, estos protocolos de regeneración pueden aplicarse a otras especies de gramíneas, comunes en pastizales naturales.

\section{Resumen}

Se desarrolló un protocolo de desinfección y regeneración in vitro de Spartina argentinensis. El menor porcentaje de contaminación se obtuvo tratando los cariopses por $60 \mathrm{~s}$ en etanol $90^{\circ}$ y 20 min de inmersión en hipoclorito de sodio al 2,5\% con Tween 20. La inducción de callos se realizó en medio Murashige y Skoog (MS) suplementado con $0,5 \mathrm{mg} \cdot \mathrm{L}^{-1}$ de ácido diclorofenoxi acético $(2,4-\mathrm{D})$ y $1 \mathrm{mg} \cdot \mathrm{L}^{-1} \mathrm{de}$

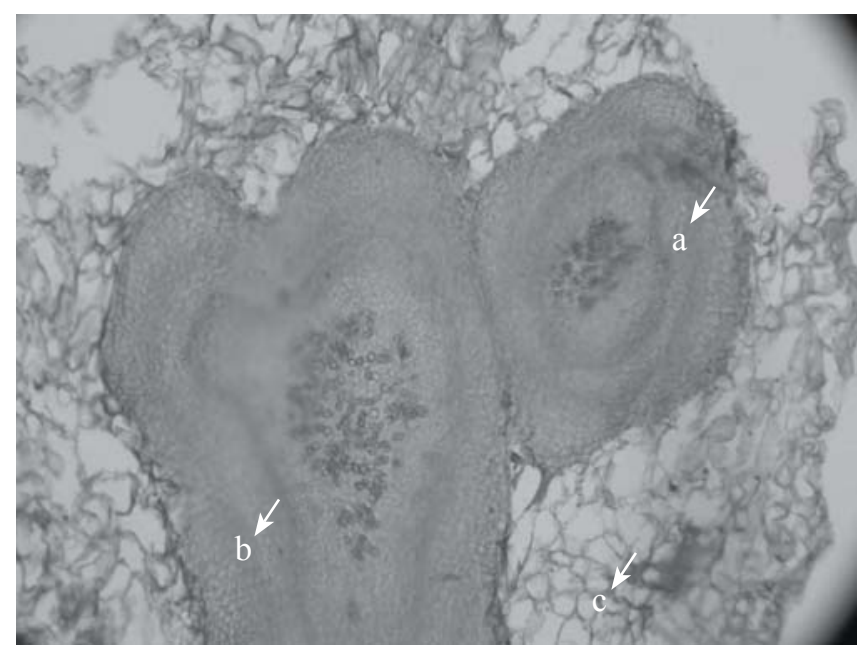

Figura 5. Corte de callo de Spartina argentinensis de 31 días obtenido de cariopses maduros en medio V1, 0,25 $\mathrm{mg} \cdot \mathrm{L}^{-1}$ BAP. Las flechas señalan la formación de vástagos, rudimento de hoja (a), cordón precambial (b) y callo (c). Barra $=10 \mu$.

Figure 5. Cross section of a 31 day old callus of Spartina argentinensis, using caryopses as explant, on V1 $0.25 \mathrm{mg} \cdot \mathrm{L}^{-}$ ${ }^{1} \mathrm{BP}$ ( 6-benzyl-adenine) as regeneration media. Arrows show shoot regeneration. a, leaf rudiment; $b$, precambial tissue, and c, callus. Bar $=10 \mu$. 
ácido indol acético (AIA). La mayor (20\%) regeneración de vástagos se logró con igual base salina y $0,25 \mathrm{mg} \cdot \mathrm{L}^{-1}$ de bencilamino purina (BAP). Se utilizó $0,025 \mathrm{mg} \cdot \mathrm{L}^{-1}$ de ácido naftalen acético para la regeneración de raíces. Las plantas se regeneraron vía organogénesis. Este protocolo es la primera mención de regeneración de plantas de $S$. argentinensis utilizando cultivo in vitro y constituye la etapa inicial para obtener variantes somaclonales. La metodología de desinfección se puede hacer extensiva a otras especies.

Palabras clave: Organogenesis, regeneracion in vitro, Spartina.

\section{Literatura citada}

Agudo-Santacruz, G., J.L. Cabrera-Ponce, V. Olalde-Portugal, M. Sánchez-González, Márquez-Guzmán, and L. Herrera-Estrella. 2001. Tissue culture and plant regeneration of blue Grama grass, Bouteloua gracilis (H.B.K.) Lag. Ex Steud. Plant 37:182-189.

Dizeo de Strittmater, C.1979. Modificación de una técnica de coloración safranina- fast green. Bol. Soc. Arg. Botánica 18:121-122.

Dutta Grupta, S., and B. Conger.1999. Somatic Embriogenesis and plant regeneration from suspension cultures of switchgass. Crop Science 39:243-247.

Echenique, V., M. Díaz, P. Polci, and L. Mroginsky. 2001. Embryogenic cell suspensions from different explants and cultivars of Eragrostis curvula (Schrad.) Nees. Biocell 25:131-138.

Feldman, S. R. 2003. Ecología de Spartina argentinensis Parodi. Crecimiento y desarrollo de la planta y efecto del fuego sobre sus poblaciones y comunidades Tesis Doctoral. Facultad de Ciencias Exactas, Físicas y
Naturales, Universidad Nacional de Córdoba, Córdoba, Argentina. 182 pp.

Feldman, S. R.; N. S. Pioli y J. P. Lewis. 2004. Caracterización de los propágulos de origen sexual de Spartina argentinensis Parodi. Revista de Investigación, Facultad de Ciencias Agrarias, Universidad Nacional de Rosario (Argentina) 4:69-73.

Johansen, D.A. 1940. Plant Microtechnique, Mac Graw Hill. NY, USA. 523 pp.

KotharI, S.L., K. Satish, R.K. Vishnoi, A. Kothari, and N.W. Kazuo. 2005. Appications of biotecnology for improvement of millet crops: Review of progress and future prospects. Plant Biotechnology 22:81-88.

Larkin, P., and W. Scowcroft. 1981. Somaclonal variation a novel source of variability from cell culture for plant improvement. Theoretical and Applied Genetics 60:197-214.

Li, X., D.M., J.A. Seliskar, J. Moga, and J.L. Gallagher. 1995. Plant regeneration from callus cultures of salt marsh hay, Spartina patens, and its cellular-based salt tolerance. Aquatic Botany 51:103-113.

Li, X., D.M., and J.L. Gallagher. 1996. Tissue culture and plant regeneration of big cordgrass, Spartina cynosuroides: implications for wetland restoration. Wetlands 16:410-415.

Murashige, T., and F. Skoog. 1962. A revised medium for rapid growth and bioassays with tobacco tissue cultures. Physiologia Plantarum 15:473-497.

Mroginski, L.A. y W.M. Roca. 1991. Establecimiento de cultivos de tejidos vegetales in vitro. Paginas 19-40. En: Cultivo de tejidos en la agricultura: fundamentos y aplicaciones. CIAT. Cali, Colombia.

Wang, J., D.M. Seliskar, and J.L. Gallagher. 2003. Tissue culture and plant regeneration of Spartina alterniflora: implications for wetland restoration. Wetlands 23:386-393. 